\title{
Trama moral e imaginarios sociales en el aprendizaje de la Independencia de la Argentina ${ }^{1}$
}

\section{Moral issues and social imaginaries in the learning of Argentina's Independence}

Alexander Ruiz Silva ${ }^{2}$

\section{Resumen}

El presente análisis se centra en los relatos sobre la Independencia que realizan los jóvenes de sectores marginales del conurbano bonaerense; se basa en la exploración de la orientación moral de sus aprendizajes e imaginarios de nación; en el papel que le atribuyen a la voluntad y al destino a la hora de explicar el origen y configuración de la misma; además de un examen de los elementos emotivos (sentimientos morales) e ideológicos presentes en sus comprensiones; los valores que configuran el constructo nosotros nación, y la manera como se articulan narrativamente en relatos fundacionales.

Los relatos analizados dejan ver trazos de esencialismo moral, dirigido a la identificación acrítica con la propia nación, y excluyen rasgos de naturaleza social o política del pasado colectivo que contribuirían a una comprensión más compleja de la historia en la escuela.

La moral sacrificial, otro rasgo a destacar dentro de los relatos, podría estar contribuyendo a justificar y enaltecer a los sujetos del presente que padecen las consecuencias más graves de la desigualdad social, lo que quizás podría desnaturalizarse desde una enseñanza de la historia en la que las orientaciones morales de lo que se aprende puedan ser sometidas a deliberación.

\section{Palabras claves}

Independencia de la Argentina, relato oficial, aprendizaje de la historia, imaginarios sociales, identificación nacional, sentimientos morales, maniqueísmo, esencialismo nacional y legitimación moral.

\section{Abstract}

This analysis focuses on stories of young people from marginalized sectors of the Buenos Aires province about the independence of their nation. The research on which the study is based explored the moral guidance of their learning and their nation imaginary, the role attributed to will and fate in their configuration, the emotional elements (moral feelings) that take part in their ideological understandings; the values that predominantly make up the "our nation" construct and how these values are narratively articulated in a foundational story. The stories analyzed indicate traces of moral essentialism leading to an uncritical identification with the nation itself and the exclusion of social or political features of the collective past that would contribute to a more complex understanding of history in school. The sacrificial moral, another remarkable feature found in the stories, could be contributing to justify and magnify subjects from present times that support the most serious burden of social inequality. This, perhaps, may be put into question in schools by means of a history teaching in which the moral guidance of what is learned can be subjected to deliberation.

\section{Key Words}

Argentina's Independence, the official story, learning history, social imaginaries, national identity, moral sentiments, Manicheism, essentially national and moral legitimacy.

Artículo recibido 26 de Marzo de 2010 y aprobado el 30 de Agosto de 2010

1 El presente documento toma algunos de los desarrollos de mi libro Nación Moral y Narración. La Argentina en los márgenes y el aprendizaje de la historia (2010) (En preparación), que se basa a su vez en mi tesis doctoral: La nación en los márgenes. Estudio de los elementos de carácter representacional, moral y político en relatos de nación de jóvenes de últimos grados de secundaria, de una escuela pública, en el conurbano bonaerense (2009).

2 Profesor asociado de la Universidad Pedagógica Nacional alexruizsilva@hotmail.com 
La mitología no es una vanidad de los diccionarios; es un eterno hábito de las almas.

Jorge Luis Borges

\section{Introducción}

Cada persona constituye una subjetividad única e irrepetible, posee un universo simbólico singular, aunque los significados que lo configuran sean, en esencia, compartibles. De hecho, tales significados han sido inicialmente adquiridos y construidos en la interacción social, aprendidos y modificados a partir de la experiencia, en la comunicación, en el encuentro con otras subjetividades que se construyen de forma similar (Ruiz Silva, 2008).

De este modo, los aprendizajes sobre el pasado del mundo social son fundamentales en la idea que cada quien tiene sobre sí mismo, tanto en términos cognitivos como en términos identitarios. Aunque estos aprendizajes no son inmutables, sí son relativamente estables a efectos de reducir la incertidumbre y fijar las bases de los siguientes aprendizajes.

La conciencia de pertenecer a una sociedad nacional es igualmente el resultado de una construcción social y, en particular, histórica. Es de suponer que las sociedades humanas pudieron tomar un rumbo distinto al de la formación de los estados nacionales que hoy se conocen, del mismo modo que nada puede asegurar que en el futuro las cosas se mantendrán como hasta ahora.

De hecho, la mayoría de los expertos en el tema coinciden en que la nación es una formación mucho más reciente de lo que la mayoría de personas tiende a creer. Se trataría, en todo caso, de un ordenamiento social que cuenta con más o menos dos siglos de antigüedad. En 1883, en un ensayo clásico sobre el tema, Ernert Renan escribió:

Las naciones son cosas bastante recientes en la historia. La Antigüedad no las conoció; Egipto, China, la antigua Caldea no fueron en modo alguno naciones. [...] La antigüedad clásica conoció repúblicas y realezas municipales, confederaciones de pequeñas repúblicas e imperios; pero nunca conoció la nación tal y como la entendemos ([1883] 2001, p. 23).
Por su parte, Benedict Anderson señala en un texto contemporáneo, igualmente paradigmático, que la formación concreta de las naciones, tal y como las conocemos, surgió a partir de la independencia y formación de estados nacionales de la América española y anglosajona entre 1776 y 1838 , en tanto entidades políticas definidas conscientemente como naciones y como repúblicas; para Anderson el estudio de la conformación de estas naciones resulta primordial:

No sólo porque fueron históricamente los primeros de tales estados que surgieron en el escenario mundial, de modo que inevitablemente proveyeron los primeros modelos reales de lo que debían "parecer", sino porque su número y su nacimiento simultáneo ofrecen un campo fértil para la investigación comparativa (1983, p. 76).

Debemos suponer que los conocimientos y convicciones de las personas acerca del origen, constitución y desarrollo de la nación propia son, en buena medida, adquiridos mediante un proceso explícito de aprendizaje de la historia en la escuela, lo que a su vez se basa en la creencia de que entre más lejos en el tiempo se ubiquen las raíces o se fije el origen histórico de la nación, mayor justificación moral y legitimidad política adquieren las apelaciones a su independencia y a la conquista de la soberanía nacional.

La forma más radical mediante la cual se expresa esta creencia es la suposición de existencia de una nación previa a su propia constitución formal. Pero, ¿cómo se producen creencias como ésta, aparentemente, tan extendidas en distintos ámbitos educativos y sociales? En el trasfondo de los imaginarios sociales de nación se encuentra la idea de un orden moral mediante el cual lo sujetos construyen una visión, tanto de sí mismos, como de la historia de la sociedad en la que viven (Taylor, 2004). En este escrito se interrogan las formas en que se asume esta idea en el contexto escolar.

Se ha decidido concentrarse en la exploración del significado de fragmentos de relatos sobre el origen histórico de la nación argentina, asociados con su Independencia de España, que producen y 
reproducen jóvenes de últimos grados de secundaria de una escuela ubicada en un sector marginal del conurbano bonaerense. El interés principal es establecer la estructura y la trama moral que otorgan sentido y articulan los relatos de los estudiantes sobre el origen histórico de la nación propia.

\section{En busca del absoluto perdido}

Las narraciones de los estudiantes sobre el origen de su nación sugieren que la Independencia argentina fue consecuencia del sentir y querer de los representantes del pueblo, de la sociedad de la época. Así, distanciarse y diferenciarse de un poder central subyugante y conquistar la capacidad de autodeterminación sólo es posible como resultado de un acuerdo de voluntades rebeldes y progresistas y de una especie de fuerza espiritual destinada a la grandeza.

\section{Federico:}

Los habitantes del Virreinato del Río de la Plata se sentían esclavizados por los mandatos del Virrey Cisneros. Ellos deseaban depender de sí mismos, tener una libre comercialización, dictar una Constitucional Nacional.

Paola:

El motivo que llevó a la independencia fue porque el Virreinato del Río de la Plata quería formar una nación [...] ya que estaba sometida bajo el poder del Rey Fernando VII, representado por el Virrey Cisneros.

\section{Leonardo:}

Digamos que Argentina tenía que independizarse. Si vamos a la realidad, es un país grande Argentina. No es chiquito como otros, no estamos hablando de países chiquitos. Digamos que es un país grande, con gente capacitada, tenía condiciones para ser un país, eso no se podía evitar.

El protagonismo de la Independencia recae en la voluntad de los habitantes del Virreinato, en la Argentina que parecía encontrarse allí, en potencia, profunda, subyacente. Sin embargo, la narración sobre el origen de la nación contempla otro elemento fundante de gran relevancia: el destino, el mismo que aparece con inusitada fuerza cuando los estudiantes son conminados a ofrecer razones y justifica- ciones sobre la necesidad de que surgiera una nación nueva. Es aquí donde emerge un cariz teleológico y prototípico en sus imaginaros de nación:

\section{Christian:}

Es como que estaban ya tomadas la decisiones. No me acuerdo bien qué había pasado con el Virrey, pero igual podría haber sido en cualquier momento. Las Provincias Unidas del Río de la Plata ya necesitaban depender de ellas solas.

\section{Carlos:}

La independencia era inevitable, ¿cómo evitarlo?, ¿quién?, si la Argentina se venía con todo.

\section{Alejandro:}

Nosotros teníamos que ser un país sin España. En mi opinión es bueno ser independiente en todo tipo.

\section{Jessica:}

Son cosas que tienen que pasar y creo que la Independencia es una de las cosas más liberales que puede haber y una de las mejores cosas que le pueden pasar a los países.

La voluntad y el destino tienen un papel determinante en los relatos sobre el origen de la nación, entrando en juego en momentos en los que se plantea una situación inicialmente conflictiva, en la que una parte de la sociedad, de la nación en gestación, se encuentra en disputa con el poder que la tiene bajo su dominio económico y político.

Las alusiones al Virreinato del Río de la Plata, a las Provincias Unidas del Río de la Plata o a la Argentina, esbozan una condición puramente nominal: una región del mundo, llámese de la forma que se llame, en ese momento o en cualquier otro, desea, quiere, independizarse; pero, en todo caso, se trata de la Argentina desde antes de serlo propiamente hasta que alcanza un cierto nivel de organización estatal, redacta una Constitución Política (18531860) y adquiere su actual nombre.

Lo que constituye este imaginario es una especie de esencialismo nacional que se basa en la creencia de que la nación subyace y antecede a su propia conformación histórica, así como en la confianza cierta en la voluntad independentista de algunos personajes cada vez más ajenos a los intereses del poder colonial. 
Johana (J):

Había mucho de los españoles acá, y cuando nos separamos, como que los argentinos empezamos a manejarnos solos, a ser independientes, digamos. [...] España era como que representante de Argentina, ¿no?

Entrevistador (E): ¿Representaba a Argentina, España?

J: Claro.

E: Pero, la Argentina no existía aún ¿̇o sí?

J: Existía, pero como que estaba limitada por España. España controlaba a Argentina. Pero existía.

Algunos estudios ya habían detectado trazas de esencialismo en la comprensión histórica de la nación. Al respecto, la investigación de María Fernanda González (2005) sobre imágenes y relatos en la construcción de la identidad nacional en estudiantes argentinos, chilenos y españoles, encontró una tendencia a concebir el territorio nacional y la nación misma como una entidad eterna que, si bien ha sufrido algunos cambios en el tiempo, parece haber estado ahí desde siempre.

El estudio de Miriam Kriger acerca de las representaciones de los jóvenes argentinos sobre el pasado, presente y futuro de su nación, halló elementos que le permitieron establecer una distinción entre una lectura histórica de la nación desde fuera, de corte cosmopolita e ilustrada, y una esencialista, desde dentro, de tipo romántico nacionalista, percibida por los estudiantes como una verdad profunda ligada al destino. $\mathrm{Al}$ respecto, añade:

Queremos destacar que en casi todos los casos en los cuales se expresa un alto grado de identificación positiva con la nacionalidad [...] La satisfacción se construye a partir de que la Argentina "es", que se contrapone a lo que los argentinos "hacen"; es decir: a pesar del devenir histórico y político, evidentemente fallido, los entrevistados parecen reivindicar un núcleo esencial de la argentinidad que permanecería ileso, incorruptible (2010, pp. $237-238)^{3}$.

3 Un análisis detallado de este tema puede verse, igualmente, en Kriger (2010).
Esta visión esencialista parece prevalecer a pesar de que la reforma educativa en la Argentina, iniciada en 1993, propició, según Luis Alberto Romero, un examen crítico del sentido común nacional:

Hubo un grupo sólido, proveniente de las universidades y del mundo académico, que trabajó en la elaboración de nuevos textos escolares, diseñó planes y currículos, capacitación y actualización o escritura de libros especializados. Su acción ha tenido un efecto perceptible: en los manuales y en otros discursos escolares se observa, aunque sea de manera parcial, la desnaturalización de la idea de nación, el cuestionamiento de su esencialidad y trascendencia, y su inclusión en el terreno profano de los procesos históricos (Romero, 2004, pp. 217-218).

Lo anterior hace pensar que la posibilidad de des-esencializar la nación en la escuela y en la sociedad y, de este modo, la irracionalidad y el dogmatismo localista a los que en ocasiones suele apelarse, requiere de esfuerzos a mediano y largo plazo, constantes y sostenidos, del sistema educativo, del mundo académico y de los medios de comunicación; pero, igualmente, de alternativas de identificación sociocultural flexibles, incluyentes y de apertura.

En los relatos de estos jóvenes escasean elementos de naturaleza social. Así, el conflicto representado se reduce al choque de dos voluntades opuestas y antagónicas: la dominante y la dominada. Este esquema disyuntivo contribuye a ubicar a unos y otros en su respectivo bando: el rey Fernando VII, el virrey Cisneros, los españoles, de un lado, y los habitantes del virreinato, quienes lideraron la Revolución de Mayo y declararon la Independencia, y los héroes del relato civilista, del otro.

Si bien no se apela mayormente a justificaciones relacionadas con la intención de dar término a formas injustas e ilegítimas de dominación, sí se esboza una especie de a priori moral, esto es, la Independencia es buena en sí misma y por serlo no requiere justificación. En palabras de Alejandro: "En mi opinión es bueno ser independiente en todo tipo". Tal consideración no puede pasar desapercibida, se formula a manera de colofón, expresa una especie de 
aprendizaje inobjetable o al menos pretendidamente inobjetable.

Esta declaración enuncia relaciones analógicas entre la búsqueda de la autonomía en el plano individual y la consecución de la Independencia en el plano colectivo, en lo social; además, el elemento moral es el que otorga sentido a los relatos de los estudiantes sobre el origen de su nación y el que articula el proceso de subjetivación del aprendizaje de la historia en la escuela. En narraciones más extensas y elaboradas nos encontramos con matices adicionales en los que vale la pena detenerse un poco.

\section{Gabriela:}

Argentina, que hasta ese entonces era El Virreinato del Río de la Plata, quería liberarse de España. España se había debilitado por la invasión de Napoleón, perdía fuerzas [...] Cisneros, el Virrey, que se encontraba en Argentina, fue encarcelado. Las consecuencias que sufrió el país fueron que después de liberarse de España no tenían quién tomara el poder y no sabían qué sistema adoptar para gobernar [...]. El tema de la independencia es un buen tema para empezar a hablar de cómo surgió la Argentina. Sin este aprendizaje no sabríamos quiénes somos y de dónde venimos y no sólo que recordemos a los más grandes, sino también a los soldados, las mujeres que ayudaron.

\section{Griselda:}

El 25 de mayo de 1810 en el Virreinato del Río de la Plata se produjo una revolución en la que participaron todos los habitantes del Virreinato del Río de la Plata, debido a que se querían independizar de los dominios españoles, y cansados decidieron reunirse los representantes del pueblo en un Cabildo y debatir sobre qué podían hacer y a la vez aprovechar que España estaba invadida por $\mathrm{Na}$ poleón Bonaparte [...]. Una de las consecuencias que se produjo después de la independencia es que Virreinato del Río de la Plata no contaba con un gobierno que lidere y no encontraba un gobernante fijo. Otros cambios que se produjeron fueron que todas las mercaderías salgan del puerto de Buenos Aires y comercializar libremente sin la oposición de los españoles. Para mí sí que nos ayudó, debido a que después de la independencia pudimos tener una Constitución, derechos e igualdad ante todo.
El tema del conflicto se destaca en estas narraciones, no sólo del lado de los otros, los españoles que dominan sus colonias de manera inestableen la medida en que han sido debilitados por un poder externo invasor (Napoleón) - sino también, y principalmente, dentro de ese nosotros que se va creando en la misma diferenciación.

En los fragmentos de los relatos se enfatiza que había que asumir las consecuencias de hacerse cargo de sí mismos, fueran cuales fueran, a la manera de externalidades negativas, como un precio ineludible que siempre hay que pagar por lo que se quiere y que comprende no sólo el esfuerzo de personajes importantes de la época, sino también el sacrificio de la sociedad en su conjunto ("mujeres, soldados").

Más allá de las precisiones e imprecisionesdesde el punto de vista historiográfico-de las narraciones de los estudiantes, es interesante fijarse en la idea de causalidad histórica que comportan: un rey debilitado, invadido, sometido, no puede hacerse cargo de sus dominios; un virrey inerme y repudiado, mucho menos. Por tanto, es el momento propicio para la emergencia de la voluntad de libertad e independencia de una nación traslapada e invisible bajo el manto del dominio externo. La nación es, al tiempo, el resultado de una voluntad de emancipación y el producto de una especie de designio del destino.

Estas narraciones de origen configuran así un proceso lógico con antecedentes y consecuentes claramente identificables, lo cual resulta clave, aunque insuficiente, en la comprensión de la causalidad histórica (Vosss, Ciarrochi y Carretero, 2004; Donovan y Bransfrod, 2005). Algunos estudios empíricos sobre la comprensión y explicación de hechos históricos paradigmáticos como el descubrimiento de América, entre otros, han permitido establecer que personas no expertas en historia tienden a explicar los sucesos de la historia atribuyendo un papel relevante a factores intencionales-de los personajes implicados-que configuran explicaciones personalistas y teleológicas (Carretero, Jacott y LópezManjón, 1994, p. 80). Al respecto, en el estudio de González, se afirma: 
Resulta llamativo que los sujetos que realizan las narraciones [de carácter histórico] más simples son aquellos que están siendo escolarizados; algunos de ellos, efectivamente, se encuentran en los últimos tramos de la educación secundaria obligatoria. Al hilo de estos resultados encontramos los derivados del análisis de la causalidad histórica. Nuevamente los sujetos más pequeños tienden a explicar la ocurrencia del Descubrimiento [de América] en términos más inmediatos, personalistas y motivados, mientras que los mayores-a partir de los 16 años-pueden vislumbrar la relación entre intenciones de personajes y su contexto histórico (2005, pp. 312 y ss.).

Al menos este último no es el caso de estos estudiantes, quienes parecen perseverar en una explicación personalista o, sería más preciso decir, voluntarista, que da cuenta del origen de una nación grande y soberana. Esta conclusión deseada, muestra el sesgo teleológico de la enseñanza de la historia escolar; de este modo, la idea de que luego del proceso independentista se ha obtenido una "igualdad ante todo", parece dar cuenta no sólo de un ideal social, sino de un formalismo memorizado y reproducido con mucha eficacia.

La preponderante función de la reproducción cultural, que históricamente ha cumplido la institución escolar, privilegia, igualmente, formas problemáticas de relación con el conocimiento. Una de estas formas es justamente la de la conclusión deseada. Esto es, que todo conocimiento debe dar una lección de vida, debe aportar algo concreto a cada persona, razón por la cual debemos valorar afirmativamente lo aprendido ${ }^{4}$.

En el campo de la enseñanza de las ciencias sociales ello supone la preeminencia de una razón pragmática del tipo: aprender historia es útil para comprender y vivir el presente (luego se volverá sobre este punto), lo que se refleja no sólo en el

4 Por supuesto, el énfasis pragmático citado no comprende todos los conocimientos adquiridos en la escuela, muchos de los cuales, independientemente del campo o área del saber en el que los estudiantes entran en contacto, suelen resultarnos inútiles, inocuos e inicuos según la condición emocional en el momento de su acceso y según las valoraciones retrospectivas posteriores que cada quien lleva a cabo. cierre de las anteriores narraciones, sino en el de la mayor parte de las producciones escritas de los chicos en la escuela.

No obstante, es posible articular consideraciones de diversa índole, esto es, la comprensión de la Independencia a partir de la interiorización de la conclusión deseada: La nación libre, grande $y$ soberana, junto a la conciencia de que existe un saldo histórico pendiente: la inocultable exclusión y desigualdad social. No se trata de asuntos necesariamente contradictorios, pues mientras en el primer caso se apela a la generalización de derechos propios de un orden nacional autónomo, en el segundo se invocan las deudas sociales que ha dejado su imperfecta conformación.

Hemos mostrado que buena parte de la justificación moral de la Independencia, en tanto hecho histórico, se basa en elementos de índole analógica, y que tales elementos se articulan en una especie de absoluto moral: algo que es bueno en sí mismo, y lo es en la medida en que se aprende como un hecho necesario e inobjetable, como el triunfo de la voluntad y como el cumplimiento de un designio del destino, en suma, como la expresión de lo inmanente: la nación que ya lo era antes de su propio origen y que debía efectivamente independizarse para poder serlo plenamente.

Pero es pertinente ver cómo se configuran los relatos de los chicos cuando se intenta, primero, promover un balance histórico de la Independencia en términos valorativos: “¿Valió la pena?”; y segundo, desajustar mediante un recurso dialéctico: “ $¿ Y$ si las cosas se hubieran sucedido de otra manera?". Esto se podría considerar como la principal finalidad ideológica de la enseñanza de la historia en la escuela, al menos en lo atinente al origen de la nación, esto es, la inculcación de una forma de representación del pasado que reduce todo a una llana relación de dominancia, en la cual, de un lado, están los sometidos, justos e insurrectos, y del otro, un poder opresor e ilegítimo.

\section{Balance valorativo:}

Entrevistador (E): ¿Valió la pena haberse independizado de España, visto hoy, en perspectiva? 
Melisa (M): Sí. Valió la pena.

E: ¿Por qué?

M: Y, sí, porque... para evolucionar, para mejorar, peor seguir dependiendo. Y, porque llegamos a lo que somos, mal que bien aquí estamos.

E: ¿En qué sentido?

$\mathrm{M}: \mathrm{Y}$ en que no tenemos que estar huyendo ni nada, es como que más o menos vivimos bien.

Carlos: Sí, a mí me parece que sí, la verdad que sí. Yo pienso que ahora no estaría hablando con usted si no estaba la Independencia.

Diego: Y yo creo que hoy en día, por lo menos en el ámbito donde yo vivo, en este lugar o en lugares donde yo me manejo eso no importa [...] En aquel momento valió la pena, yo creo que sí, en aquel momento, ahora no sé.

Más allá de cualquier externalidad negativa considerada-de los errores cometidos, de los sacrificios y las injusticias producidas y padecidas-la nación existente parece justificar en sí misma todo lo ocurrido en el pasado. Lo indefectible impone su patencia: el tiempo no tiene vuelta atrás; lo pasado, pasado. Por tanto, nos queda lo que somos, en palabras de Melisa: "Y, porque llegamos a lo que somos, mal que bien, aquí estamos"; y de Carlos: "Yo pienso que ahora no estaría hablando con usted si no estaba la independencia". Sin embrago, contrario a lo que pudiera parecer, no se produce una suspensión del juicio moral sobre los acontecimientos de la historia, sino más bien una subordinación de dicho criterio.

El criterio deontológico: la nación que deberíamos haber sido o que podríamos ser, se subordina a uno ontológico: la nación que somos. De este modo, la nación deviene en absoluto moral: es buena en sí misma, y lo es en tanto realidad existente. Las situaciones justas e injustas alrededor de su origen y conformación no admiten distinción o cuestionamiento. De la conjunción o acumulación de tales situaciones resulta una realidad inapelable: la Argentina real y palpable.

Sin embargo, podemos encontrar notables excepciones a esta regla; aunque la opinión de Diego otorgue igualmente una valoración positiva al origen mismo de la nación, él no se encuentra seguro de extrapolar esta misma valoración al presente vivido. Sus dudas al respecto se relacionan con sus actuales condiciones de vida. Diego comparte con la mayoría de sus compañeros de escuela una condición socioeconómica precaria, pero, a diferencia de buena parte de ellos, él debe trabajar y estudiar.

Él es el principal sustento económico de su familia y ha manifestado en repetidas ocasiones, a sus profesores, y en una parte del diálogo que aquí se reproduce, su inconformidad con un trabajo duro que además de agotador le resta tiempo a los deberes de la escuela y a las diversiones propias de un chico de su edad.

Diego (D):

A mí no me gustaría que me usen para qué sé yo... "dame un voto y yo te doy, qué sé yo, tres mil pesos". No, yo no. Yo soy libre de expresarme como quiera y no me voy a dejar obligar nunca a hacer algo que no me gusta. Ah, yo quisiera seguir estudiando, llegar a ser profesor, todas esas cosas, porque a mí me gusta estudiar. Pero muchas veces, por la sociedad en que vivo, uno tiene que trabajar.

E: ¿Tú trabajas, verdad?

D: Claro, yo trabajo, entonces a mí todo me resulta difícil "o el trabajo o la escuela”. Yo trato de hacer las dos cosas, pero me perjudica porque muchas veces no tengo tiempo para hacer las cosas que piden acá en la escuela.

E: ¿Qué haces, Diego?

D: Soy carpintero, trabajo en una mueblería, lijo, doy color, vendo.

E: Y eso te demanda mucho tiempo.

D: Claro, me quita mucho tiempo. A la mañana estudio y después a la tarde, desde las dos, tres, más o menos, hasta las ocho de la noche, trabajo. Y cuando no vengo a la escuela, trabajo todo el día. De ocho a una y de tres a ocho. Y muchas veces para el que se esfuerza es más difícil que para el que no se esfuerza. Siempre me pregunto por qué, así también el que tiene más poder contra el obrero. Pero si no hubiese obreros no existirían los políticos, creo yo, porque si un político hace 
una obra ¿qué sé yo?, una plaza, un edificio, una municipalidad, si no hay obreros, eso no se levanta. Un político no se va a poner a ensuciar las manos para hacer un revoque, para levantar una pared, yo creo que no; y sin embargo, a esa gente es a la que más atacan.

De manera crítica y vivencial Diego se aleja de la pregunta inicial, pero ilustra a la vez que con seguridad la Independencia de la nación valió la pena para la gente del pasado; su configuración actual valdrá la pena, tal vez, para los aventajados o privilegiados de hoy, pero a juzgar por su propio presente, tal valoración se pone en suspenso, cuando no en directo cuestionamiento. En este sentido, Egan ha señalado que:

Constantemente modificamos la importancia que damos a los sucesos de nuestra vida a la luz de nuevos acontecimientos. Estas modificaciones no son el resultado de unos simples cálculos lógicos; más bien son el resultado de unas evaluaciones efectivas que atribuyen unos significados emocionales a esos acontecimientos (Egan, 2000, p. 97).

Las condiciones existenciales de las personas influyen en la construcción de sus imaginarios de nación, e incluso, en algunos casos, éstos desafían la eficacia simbólica de los sesgos positivos de la enseñanza de la historia en la escuela. Esta tensión se sostiene en distintos momentos del diálogo con los jóvenes y es especialmente notoria cuando aparecen situaciones personales verdaderamente dramáticas.

\section{Una moral de buenos y malos}

Volviendo al artificio dialéctico, antes anunciado, mediante el cual se les propuso a los participantes un escenario hipotético radicalmente distinto al aprendido (historia contra-fáctica), los estudiantes expresan una marcada resistencia a seguir el curso de versiones alternativas.

Entrevistador (E): Y si el de aquella época hubiera sido un buen gobierno, si el virrey Cisneros hubiese sido un gobernante justo, ¿habría valido la pena intentar independizarse?
Jessica:

Sería muy de vendida si digo eso [risas]. Digamos, realmente creo que si uno está bien no necesita a veces modificar las cosas, pero seguro luego íbamos a estar mal, peor. Obviamente no estábamos bien, el gobierno no estaba muy bien, así que sí, valió la pena.

Christian (C):

No, yo creo que no. Porque ya seríamos independientes, pero también dependientes porque nosotros queríamos tener un presidente y un gobierno propio, no depender de otros. Cada país tiene su forma de gobernar, o sea, ellos yo creo que para eso tienen su país y que ellos pongan reglas en su país, nosotros tenemos nuestras reglas, eso pienso yo.

E: Bueno, el asunto se resolvió a favor del ejército patriota, y si se hubiera resuelto en contra, es decir, si los españoles hubieran ganado la guerra y se hubieran mantenido en el poder, ¿haberlo intentado, haber intentado independizarse, hubiera merecido la pena, aunque al final se hubiese perdido?

C: Sí, porque no bajamos los brazos, seguimos adelante, siento yo. Que por más que hayamos perdido, porque siempre en las guerras... en las Malvinas también, en la guerra de las Malvinas también perdimos y perdimos un montón de gente, hubo un montón de fallecidos. Y sin embargo, seguimos adelante, como que no nos quedamos porque perdimos.

E: Sí claro, pero ¿valió la pena haber perdido todas esas vidas en las Malvinas?, ¿qué opinas?

C: Y... no, en parte la gente desaparecida eso como que es muy feo. Para mí como que la guerra de las Malvinas no valió la pena, pero la de Independencia sí porque esa la ganamos.

$\mathrm{Al}$ "neutralizar" el proceder injusto del gobierno colonial con la pregunta: “ $i s i$ el virrey Cisneros hubiese sido un gobernante justo?", Jessica afirma tajantemente: "pero seguro luego íbamos a estar mal, peor" y Christian concluye, a pesar de las dudas que le generan las pérdidas humanas producidas por las guerras: "Para mí como que la guerra de las Malvinas no valió la pena, pero la de Independencia sí porque esa la ganamos". Mientras Christian se apoya en la certeza del aprendizaje de la versión basada en 
ganadores y perdedores absolutos, Jessica apela, no sin ironía, a un sentimiento de lealtad: "Sería muy de vendida si digo eso".

En todo caso, con relación a la Independencia, los estudiantes han interiorizado el esquema basado en una relación de dominancia quebrantada, esto es, un poder opresor e ilegítimo: ellos, los finalmente derrotados, y una fuerza emancipadora y justa: nosotros, los ganadores definitivos. La historia aprendida da cuenta de la interiorización de este imaginario social restringido, y aquí viene lo paradójico, exclusivamente al pasado de la nación, sin aplicación posible al curso de la sociedad actual.

Los jóvenes pueden destacar la vigencia de otro tipo de dominancia. De hecho, algunos de ellos lo hacen cuando aluden a la influencia económica y política que ejercen potencias extranjeras sobre la Argentina:

E: ¿Es la Argentina una nación independiente, hoy?

Gabriela:

Y no sé, cuando ya estaba formada Argentina, por ejemplo, Rivadavia fue el primer presidente, creo que fue el primer presidente que fue y pidió un préstamo, ¿no?, al exterior y ya. ¿Qué teníamos? Una deuda. Mucho después vinieron los militares y ahora teníamos una gran deuda, después vino Menem y ahora tenemos una deuda, un choclo así de grande. Que los que son vivos, las personas que nos prestaron, que son Estados Unidos, nos prestaron la plata y nos dijeron: "ustedes no me devuelven la plata, pero nosotros sacamos tierra". Y no son tontos para elegir la tierra, porque eligen la parte de la Patagonia donde tenemos agua, porque sabemos que, qué sé yo, dentro de treinta, cincuenta años, agua ya no vamos a tener más.

Paola:

Sí, en algunos lados sí, pero, ya prácticamente estamos vendidos a Estados Unidos. Y hay algunos lugares donde, por ejemplo, ya vendrían a ser las petroleras, ningunas son nuestras. Hay tierras que también fueron vendidas a Estados Unidos. Lo que se podría diferenciar es que, bueno, tenemos obviamente un poco más de libertades que otros países que están más oprimidos, por ejemplo, Irak, que está totalmente invadido.
Diego:

Y está Estados Unidos y están los países europeos. Porque eso yo creo que está todo armado como para que uno siempre se sienta inferior a ellos. Pero yo creo que en el espacio no hay un arriba y un abajo, no hay un norte ni un sur, ni un este ni un oeste y eso me molesta a mí, ¿por qué los países que están del sur siempre son los países bajos y en el norte siempre los altos?, ¿por qué no el mundo se da vuelta?, ¿por qué no nos venden un mapa de cabeza?

En estas narraciones el pasado aprendido se toma de manera analógica en relación con la percepción que se tiene del presente, sin mayor solución de continuidad, como si también en el infortunio la nación describiera los signos de su destino. Aunque, al mismo tiempo una minoría de estudiantes, personificada en estos tres chicos, permite dar cuenta del esfuerzo de hacer un uso pragmático de lo aprendido sobre la historia nacional.

Quizás valga la pena mencionar que días después de estos diálogos busqué a Diego para mostrarle el mapa que hiciera célebre Joaquín Torres García, en el que el Norte se ubica abajo y el Sur arriba (Ilustración 1), representación utilizada, entre otras cosas, para desafiar las convenciones reproducidas en los atlas y libros de texto de distintas épocas, que según la perspectiva de Torres han contribuido a naturalizar un orden simbólico jerárquico entre el Norte y el Sur 5 . Diego se sorprendió con el mapa y no tardó en señalar el parecido con lo que él pensaba, o más bien, con lo que lo indignaba.

5 Este mapa, como es sabido, aunque por supuesto, mucho más el pensamiento de Torres García sobre América latina, ha sido inspirador de valiosos análisis y enfoques críticos sobre las relaciones de dominancia Norte-Sur y sobre los nuevos colonialismos que dichas relaciones producen y reproducen. La reflexión base que acompaña el mapa es la siguiente: "No debe haber norte, para nosotros, sino por oposición a nuestro Sur. Por eso ahora ponemos el mapa al revés, y entonces ya tenemos justa idea de nuestra posición, y no como quieren en el resto del mundo. La punta de América, desde ahora, prolongándose, señala insistentemente el Sur, nuestro norte" (Torres García, 1941, p. X).

Sobre una mirada crítica a las nuevas relaciones de dominancia entre los dos hemisferios ha habido una profusa producción teórica. De una larga y variada lista, en cuanto a enfoques, énfasis y tópicos de análisis pueden resultarle a lector de mucha utilidad la revisión de los trabajos de Rama (1982); Quijano (1993); Escobar (1996); Mignolo (2000); Monsivais (2000); Borón (2000), entre otros. 
Ilustración 1. Reproducción de la obra América invertida (versión) de Joaquín Torres García, 1943.

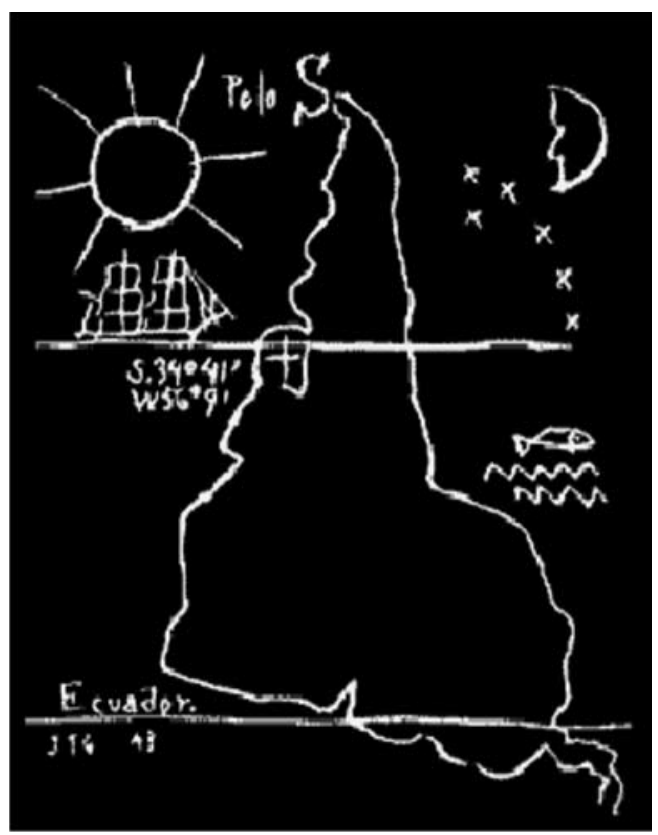

Fuente: Museo Torres García, Montevideo, Uruguay.

Diego (D): ¿Me podés regalar una copia del mapa?

E: Claro, este es para ti. ¿Qué vas a hacer con él?

D: Y, lo voy a pegar en el taller, en la carpintería [risas].

Más allá de lo anecdótico de esa situación, es importante destacar el papel que cumplen la observación y la reflexión de la experiencia propia en relación con los contenidos aprendidos en la escuela. En el caso de Diego y de muchos otros estudiantes, los conocimientos formales pasan por el tamiz de la propia conciencia sobre la realidad social vivida y sobre las condiciones del entorno. Se trata de una especie de pensamiento crítico por contraste entre los ideales de los aprendizajes formales y la comprensión de las demandas concretas de la vida de todos los días.

Los nuevos esquemas de dominancia ya no se plantean en términos absolutos, se relativizan en función de los complejos intereses de distintos ac- tores y sectores nacionales. Sin embargo, pareciera que en la escuela cuanto más lejanos en el tiempo sean los hechos configurados históricamente, y más vinculados se encuentren al surgimiento mismo de la nación, más se promoviera, justamente, la mitificación de un tiempo de origen y la rotunda diferenciación del nosotros - ellos.

Así, perviven en los relatos de los estudiantes dos naciones nítidas pero incorpóreas: una, en tanto realidad del pasado que parece disolverse en medio de un clima de ilegitimidad: la nación imperial que se fragmenta y pierde sus dominios en ultramar; y otra, en tanto proyecto indeterminado, esto es: la nación en proceso de construcción y definición, distinción posible sólo a partir del reconocimiento de tensiones y luchas internas.

Una misma línea argumental recorre el surgimiento de la nueva nación Entre el fin del Virreinato y la declaración de Independencia de las Provincias Unidas: la idea de defensa. Por un lado, la defensa de los dominios españoles en América, por el otro, la defensa de intereses de los nacidos en América, de un nuevo orden económico y jurídico, de los nuevos derechos adquiridos por parte de los propietarios y, finalmente, de la capacidad de autodeterminación y soberanía nacional a partir de la Constitución de la Nación Argentina de 1853-1860.

Una de las apuestas esbozada en este escrito es que la nación es un constructo articulado defensivamente. Los imaginarios sobre su origen se construyen con base en un recurso apologético, por ello no es de extrañar que la educación, especialmente la enseñanza de la historia, haga tanto hincapié en ello, incluso al punto de mitificar esta idea. Así, los testimonios de los chicos indican la lucha de dos naciones claramente preexistentes, aunque la historiografía indique que la Independencia del Virreinato es sólo el inicio de la azarosa configuración de una nación en ciernes.

Términos como "voluntad" y "destino" son tributarios de este imaginario defensivo, y si bien se contraponen en principio, pues ante lo predeterminado poco o nada pueden influir las decisiones y acciones de las personas $y$, al contrario, si un hecho 
ha sido o es el resultado de la voluntad de individuos y de grupos sociales específicos no hay designios secretos o profecías divulgadas que se antepongan a su impulso transformador, la Independencia de la nación es el resultado de la voluntad de hombres elegidos que parecen haber aceptado su destino, esto es, hacerse cargo o ser protagonistas del origen de la nación, legado esencial para las generaciones venideras. Voluntad y destino aquí están lejos de contraponerse.

Al contrario, se complementan, juntos presuponen además, la eliminación del azar. Los jóvenes aprenden que la nación debía ser, desde un principio, e incluso que ya lo era desde antes, desde un antes inmemorial e indefinido, y que sólo se requerían personas decididas y valientes que se hicieran cargo de actualizar lo inevitable. Esto, antes que restarles méritos a dichos personajes, los muestra en el esplendor de su gloria.

Eliminar el papel del azar en la historia y hacer depender el curso de la misma de la voluntad indefectible de unos cuantos elegidos contribuye, como se ha intentado mostrar aquí, a la construcción de ideas esencialistas sobre el origen histórico de la nación. Si este mismo esquema se traslada a la comprensión del presente, esta forma de enseñanza de la historia en la escuela puede estar contribuyendo a la construcción de una visión en la que la iniquidad social se naturaliza y los chicos de sectores marginales asumen con resignación su condición subordinada. Si la escuela renuncia a la promesa, pronto los estudiantes declinan la esperanza; por tanto, ¿qué tipo de historia aprendemos y de qué manera no son precisamente asuntos inocuos?

\section{Actores, valores y legitimación moral}

El relato oficial sobre la Independencia y el origen histórico de la nación apropiado y reproducido por los estudiantes no es, de ninguna manera, moralmente neutral. Los estudiantes construyen y expresan diversas valoraciones en sus reconstrucciones narrativas en relación con los personajes de la Independencia considerados importantes. En toda trama narrativa existen distintos grupos de personajes a los que se les atribuye intenciones e in- tereses específicos, no siempre conciliables, e incluso muchas veces contradictorios (White, 1973)6.

Como hemos señalado antes, en los relatos de los estudiantes se identifican dos grupos de actores: de un lado, quienes luchan por la Independencia de la nación nueva; y del otro, quienes pretenden impedirlo. En esta instancia los grupos se conciben de manera amplia y moralmente homogénea; el primero es, como pareciera obvio, el referente de identificación que constituye un nosotros nacional primigenio, del lado del cual se encuentran la razón y valores tales como la libertad, la valentía y la solidaridad; el segundo hace las veces de referente de diferenciación, que agrupa en un ellos genérico a los representantes del régimen imperial, exentos de razón y defensores de valores e intereses como la autoridad, la ambición y la lealtad, en sus acepciones negativas?.

En un número reducido de relatos, el primer grupo de valores se presenta de manera segmentada.

6 Para Hayden White: “La escritura histórica es un medio de producción de significado. Es una ilusión pensar que los historiadores sólo desean contar la verdad acerca del pasado. Ellos también quieren, lo sepan o no, pero en cualquier caso deberían querer, dotar al pasado de significado" (2003a, p. 52). Esto aplica tanto para los historiadores profesionales como para los consumidores y reproductores de sus versiones históricas. La idea misma de trama se define en relación con la intención del narrador; el mismo autor da cuenta de lo que sería una explicación por la trama en los siguientes términos: “Se llama explicación por la trama a la que da el "significado" de un relato mediante la identificación del tipo de relato que se ha narrado. Si en el curso de la narración de su relato el historiador le da la estructura de trama de una tragedia, lo ha "explicado" de una manera, si lo ha estructurado como comedia, lo ha "explicado" de otra. El tramado es la manera en que una secuencia de sucesos organizada en un relato se revela de manera gradual como un relato de cierto tipo particular" (White, 2003b, p. 18; énfasis original).

En un trabajo posterior agrega: "Cómo debe ser configurada una situación histórica dada depende de la sutileza del historiador para relacionar una estructura de trama específica con un conjunto de acontecimientos históricos a los que desea dotar de un tipo especial de significado" (White, 2003b, p. 115).

7 Los valores atribuidos al nosotros nación adquieren aquí la siguiente connotación: libertad, decisiones y acciones en favor de la liberación, la autonomía y un gobierno propio; valentía, acciones de patriotismo, heroísmo, entrega o sacrificio; y solidaridad, protección a personas o grupos sociales desfavorecidos de la naciente nación. Por su parte, los valores atribuidos al régimen español se entienden de la siguiente manera: autoridad, dominación e imposición de decisiones; ambición, explotación y sometimiento de los otros en condiciones de esclavitud; $y$ lealtad: fidelidad o adscripción voluntaria al mandato español o simple acatamiento de su gobierno. 
Así, se reconoce y expresa una sociedad jerárquica con acceso diferencial al poder y con distintos niveles de vulnerabilidad social. Los valores mencionados siguen cobijándolos a todos, aunque no en el mismo grado, pues quien más arriesga es quien más plenamente los representa, esto es, los próceres del relato civilista (Saavedra y Moreno, particularmente), los héroes del relato marcial (San Martín y Belgrano, especialmente), y algunos anónimos representantes del pueblo entre quienes se menciona a campesinos, soldados e indígenas.

Quienes menos arriesgan participan de dichos valores en menor grado: se trata de personas que si bien apoyaron la Independencia, no descuidaron o subordinaron a ésta sus propios intereses. Entre éstos se mencionan en abstracto a los poderosos, ricos y políticos españoles nacidos en América.

Vale la pena advertir que estos valores no fueron considerados de forma excluyente; se registraron según su presencia o no en cada una de las narraciones de los estudiantes. La preeminencia de un valor sobre los otros indica, a su vez, el tema que articula el relato. Para James Wertsch (1998), el tema se relaciona con los objetivos que se atribuyen a los actores y con los motivos subyacentes a esos objetivos.

En nuestro caso, la libertad se encuentra presente en todos los relatos escritos y orales; la valentía alcanza notoriedad sólo cuando en el diálogo aparecen la guerra y la solidaridad como aquello que sólo es posible de forma parcial, una vez lograda la Independencia, y como motivación previa a la misma.

A propósito de un estudio sobre el aprendizaje de la historia de los Estados Unidos, relacionado con la Revolución y el origen de la nación, Wertsch (1998, p. 143) enfatiza que el tema dominante en los relatos de los chicos de secundaria es el de la "búsqueda de la libertad" y añade que dicho aprendizaje prácticamente consiste en el dominio de una herramienta cultural básica: la narración oficials.

En concordancia con este hallazgo, la libertad es en nuestro contexto el tema y el valor que ordena

8 Entre los estudios citados por Wertsch se encuentran los trabajos de Beck y McKeown (1994); Wertsch (1994) y Wertsch y 0'Connor (1994). todo el relato, e incluso articula las narraciones en las que se cuestiona la realización histórica de dicho valor o su vigencia actual. Así lo ilustran los siguientes fragmentos de relatos, al igual que los otros valores atribuidos al nosotros nación. Veamos:

\section{Leonardo:}

Como siempre, la sociedad estaba dividida. Digamos que la gente que quería depender de sí misma, qué se yo, que la Argentina se agarrara y se mantenga sola y sea libre y la gente que quería seguir bajo el dominio de España, por miedo. Digamos que siempre existe el miedo de que, digamos, la gente que se asusta. No toda la gente es igual, no toda la gente tiene la misma forma de pensar. Digamos que mucha gente habrá querido independizarse y luchó por la libertad y se logró. Mucha gente, bueno, no quiso eso pero a la fuerza lo tuvo que aceptar [Libertad].

Melisa:

Es como que necesitábamos liberarnos y formar nuestra propia nación, nuestra propia República.

E: ¿Qué tipo de cosas te parecieron más interesantes, que valga la pena destacar?

M: Y la liberación en sí, porque, más allá de que hubo diferentes intereses, dentro de todo hubo una evolución en la libertad para todos [Libertad].

Carlos:

Necesitábamos un gobierno propio, libre, pero igual están los que se quedan con más y están los que se quedan con menos. Igual sería en el sentido de que unos tiene más cosas que otros y también más libertad, así se diga que todos somos igual de libres [Libertad].

Diego:

Habrá habido algunos que como que se sentían obligados y otros que eran como muy patriotas y querían hacer algo, ¿no?, querían ser como un punto esencial de toda esa guerra. Y, sí, muchos habrán sido muy patriotas y les habrá gustado ir [Valentía] y muchos debe haber que no, tal vez habrán ido obligados para que se haga más bulto en la cantidad de soldados que había. Creo que así como que se juntaron dos o tres importantes políticos para independizar nuestro país, después se juntó un grupo más grande de gente, ¿no?, de 
clase obrera para que también se libere más la parte social del pueblo [Solidaridad].

\section{Gabriela:}

Te dicen: "San Martín fue un gran héroe porque cruzó los Andes" y nada más. Pero también liberó a Perú, a la Argentina, es decir, que solamente lo grande que hizo fue cruzar los Andes, y nada más. Después de todas las cosas que hizo, no se habla más nada. Y no cruzó solo, cruzó con todo su ejército, con toda su gente, él solo no cruzó [Valentía].

E: ¿Te refieres a las personas que pelearon esa guerra?

G: Claro, para mí tienen que tener su reconocimiento.

E: ¿Qué tipo de reconocimiento sería?

G: Como que se los tenga en cuenta, que se diga quiénes fueron, qué indios, qué peones. San Martín organizó todo, ¿quién va a decir que no?, fue la cabeza, pero el cuerpo fue la gente de atrás [Valentía, Solidaridad].

En los relatos en los que los valores preeminentes son la valentía o la solidaridad, de todos modos la libertad mantiene una notoria presencia o se encuentra de forma tácita en la narración. Mediante este valor se expresa una concepción romántica de la historia, tendencia que coincide con los hallazgos de otros estudios realizados en contextos escolares en Iberoamérica (Kriger, 2007; Carretero, 2007, Carretero y Kriger, 2006a y 2006b; Rosa, 1994; González, 2005, entre otros).

Es necesario resaltar que en este contexto socioeconómico la orientación romántica del relato se concentra en el papel moral que se atribuye a los protagonistas de la Independencia, a sus decisiones y actuaciones heroicas, aunque ello sólo alcanza para producir una idealización de sus consecuencias para la sociedad de la época, no para el futuro de la nación. En suma, el romanticismo del relato marcial es equilibrado por el realismo del relato civilista, y se entiende que ambos hacen parte de una narración más amplia y abarcadora.

Por su parte, los antagonistas del relato son comprendidos de forma genérica bajo el término: españoles. Salvo las menciones concretas al Virrey
Cisneros y al Rey Fernando VII, no hay antagonistas con nombre propio, ni siquiera en el relato marcial, lo cual es llamativo si se tiene en cuenta que la figura del héroe suele constituirse en contraste con los valores que representan determinados enemigos.

En relación con esto, vale la pena aludir al relato oficial de la guerra de Independencia en el Virreinato del Nuevo Reino de Granada, en el que personajes como Pablo Morillo (más conocido como "el Pacificador”) y José María Barreiro (general de la Corona española) representan la forma más radical y odiosa del ellos imperial, especialmente por anteponerse a la figura cuasi-mítica de Bolívar; veamos ahora algunas opiniones en las que se expresan los valores más frecuentemente atribuidos a los antagonistas de esta historia aprendida:

\section{Lorena:}

Para mí punto de vista España decía con qué países se tiene que comerciar. Por ejemplo, si quería comerciar con otro país que no fuera el que España quería, tendría serios problemas, y la plata que juntaban los que comerciaban, una parte se lo quedaba el rey [Autoridad, Ambición].

Paola:

Estaban del otro lado del mar y querían mandarnos desde ahí porque a nosotros más que nada nos usaban para tener sus recursos [Autoridad]. Los de España, por ejemplo, no tenían mucha tierra, entonces nos utilizaban a nosotros para tener más [Ambición].

Jessica:

Los españoles vinieron acá, invadieron todo, se apoderaron de América... y usurparon de todos nosotros [Ambición].

Gabriela:

En la Asamblea de 1813 se quería hacer una Constitución, pero ¿qué pasaba? La mayoría eran españoles y obviamente iban a tirar para España, ¿no?, para ellos. Por eso fue un fracaso querer hacer una Constitución en ese momento [Lealtad].

Melisa:

Una parte si estaba de acuerdo con independizarse y otra parte no, porque también, todos los que habían emigrado para la Argentina, capaz estaban de acuerdo con seguir dependiendo [Lealtad]. 
La referencia a la libertad exigida o buscada por los protagonistas plantea como contra-cara la lealtad a la Corona, que guía a los antagonistas del relato. Por otra parte, una línea muy tenue distingue la autoridad de la ambición; así, mientras la autoridad expresa una dominación ilegítima, la ambición hace manifiesto un dominio desmedido o abusivo. Este último contravalor aparece con mucha fuerza con la aparición en la escena narrativa de la guerra, sólo en contadas excepciones los valores de los protagonistas son atribuidos a los antagonistas o viceversa; los pocos casos en los que ello ocurre, se hace notorio un intento de lectura crítica de la historia oficial.

Esta atribución de valores a los personajes del relato permite vislumbrar dos esquemas morales que organizan el contenido y sentido de la historia enseñada: uno de ellos es una suerte de maniqueísmo moral mediante el cual cada personaje citado pasa a ocupar un lugar, en el extremo del bien o en el extremo del mal, sin medias tintas, sin posiciones intermedias o neutrales. Bajo este esquema, los antagonistas, los españoles victimarios, explotadores, abusivos, representan el mal; y los protagonistas, tomados como bloque, los héroes, próceres, el pueblo, las víctimas, representan el bien.

El otro esquema, fruto del anterior, da cuenta de una escala moral mediante la cual se expresa un complejo juego de intereses de los distintos actores involucrados en la Independencia y en el origen histórico de la nación. Aquí se lleva a cabo una distribución de responsabilidades según el nivel de sacrificio atribuido a cada grupo o personaje, pero especialmente según el valor simbólico asignado a su legado. A quien más se atribuye riesgo o pérdida, y con ello aportes a la patria, más alto se lo ubica en la escala. San Martín estaría situado, en todo caso, un peldaño más arriba que el resto de los protagonistas en la mayoría de los relatos marciales o, cuando menos, en el mismo lugar que el anónimo pueblo, en los relatos más críticos.

La relación entre estos esquemas configura la trama moral del relato; en ella y desde ella los estudiantes asignan funciones valorativas específicas a cuatro grupos de actores: los representantes del imperio español (Rey, Virrey); los políticos locales
(Moreno, Saavedra); los héroes militares (San Martín y Belgrano) y el pueblo (campesinos, indígenas, soldados) ${ }^{9}$. A Napoleón Bonaparte, mencionado en muchos de los relatos, se le asigna una importancia relativamente incidental, en tanto facilita, sin proponérselo, la Revolución de mayo, por tanto, al ser desprovisto de voluntad o intención en la generación de la Independencia de la nueva nación, no le es asignado rol moral alguno.

En suma, los valores morales positivos son atribuidos a los protagonistas de manera gradual, en relación con los sacrificios que se les atribuye. Esta moral del sacrificio pareciera contribuir al mantenimiento de un imaginario social que justifica y enaltece a los sujetos del presente que padecen las consecuencias más graves de la desigualdad social, a pesar de que tengan la certeza de estar obteniendo muy poco de la sociedad nacional en la que viven; pero, como señala Taylor, reconocer la fuerza de un imaginario no siempre significa que todos estén dispuestos a aceptarlo.

Tal y como se ha intentado mostrar en este escrito, la gran narrativa de nación tiene un peso enorme en los imaginarios sociales de estos jóvenes que viven y se educan en un contexto marginal, del mismo modo que la historia aprendida influye notoriamente en la comprensión que cada quien tiene de sí mismo.

\section{Consideraciones finales}

La interiorización del relato oficial, a fuerza de repetición de una serie limitada de elementos narrativos culturalmente dispuestos para el consumo escolar, en los que difícilmente tienen lugar la pregunta, la duda, las versiones alternativas y mucho menos la

9 El término criollo no aparece en ninguno de los relatos de este grupo de estudiantes. No se trata de un dato menor si se tiene en cuenta que suele ocupar un lugar visible en los libros de texto y el abordaje del tema en otras naciones latinoamericanas. Vale la pena recordar que tal término comprende, de forma genérica, a los españoles nacidos en América, y compendia una condición socialmente abarcadora en la que se suele incluir desde la clase económicamente acomodada, especialmente grandes comerciantes, hacendados y funcionarios de los Virreinatos, hasta una parte inespecífica del pueblo, entre ellos, estancieros y pequeños comerciantes. Es posible que se trate de un concepto poco esclarecedor para estos estudiantes y de difícil asignación en términos identitarios. 
deliberación, es un reflejo de lo que Wertsch (2004) ha denominado saber ventrílocuo.

Tal y como hemos mostrado aquí, no son muchos los chicos que logran distanciarse de la reproducción de convenciones "aprendidas" de dicho formato estándar, lo cual confirma, de alguna manera, la vigencia institucional de la gran narración o narración maestra a la que ha aludido el mismo Wertsch (2004) con respecto a la enseñanza de la historia, y Ricoeur (2000) con respecto a la historiografía en general. Este tipo de narración cierra el universo simbólico del intérprete en una serie de hechos verdaderos, personajes importantes y consecuencias directas e indirectas que no admiten mayor consideración.

Las narraciones sobre la independencia expresan una tendencia esencialista y ontológica de la nación. Sus relatos revelan creencias sobre una entidad que subyace y antecede a su propia conformación histórica, algo que es bueno en sí mismo y que lo es en la medida en que se aprende como un hecho necesario e inobjetable, como el triunfo de la voluntad y el cumplimiento de un designio del destino; en suma, como la expresión de lo inmanente: la nación que ya era nación antes de independizarse y que debía efectivamente independizarse para poder serlo plenamente.

Este tipo de visión, según lo indican distintos estudios, (Barton Levstik, 2004 y 2008; González, 2005; Romero y cols., 2004, Carretero, 2007, VanSledrijt, 2008, entre otros) se ha encontrado en estudiantes de clase media, aunque muy pocas veces ha sido explorado en contextos marginales. Adicionalmente, los relatos analizados indican que el esencialismo atribuido a la nación ensombrece o excluye los rasgos de naturaleza social o política del pasado colectivo que contribuirían a una mejor y más compleja comprensión de la historia en la escuela.

La presencia de una narrativa esencial de la nación muestra, aquí, una relación complementaria del papel asignado a la voluntad y al destino en la configuración discursiva de la nación. Su inextricable vinculación se dirige, principalmente, a la eliminación del azar en la explicación de su origen histórico. Los jóvenes aprenden que la nación debía ser desde un principio, e incluso, que ya lo era desde antes, desde un antes inmemorial e indefinido y que sólo se requerían personas decididas y valientes que se hicieran cargo de realizar lo inevitable.

Los elementos de tipo ontológico: la nación que somos; y esencialista: la nación que estábamos destinados a ser, que caracterizan los relatos de estos estudiantes, terminan subordinando otros de orientación deontológica: la nación que deberíamos haber sido o que podríamos ser, de tal modo que el imaginario de nación construido deviene en absoluto moral, esto es, la nación es buena en sí misma, en tanto realidad existente, por lo que las situaciones justas e injustas alrededor de su origen y conformación no admiten mayores cuestionamientos.

Poner en cuestión el relato oficial, que sirve de vehículo a este tipo de certezas, equivaldría a cuestionar el orden moral construido y sostenido en dicha versión. Un "correcto aprendizaje" de asuntos referidos a la Independencia de la nación propia implica una orientación valorativa específica en relación con los hechos, sucesos o acciones que se consideran moralmente correctos, es decir, que debieron y debian ocurrir. Esta idea de lo moralmente correcto e indudable representa lo sacro del relato. Por ello la forma de escritura y de narración privilegiada aquí es la de la reproducción.

Los estudiantes recurren a dos tipos de esquema en la asignación de roles morales a los protagonistas y antagonistas de sus relatos. El primero, es una forma de maniqueísmo moral mediante el cual cada personaje citado pasa a ocupar un lugar, o en el extremo del bien o en el extremo del mal, sin matices, sin posibilidad de intermediación o de relativización.

El segundo esquema da cuenta de una suerte de escala moral mediante la cual se expresa un complejo juego de intereses de los distintos actores involucrados en la Independencia. Aquí se lleva a cabo una distribución de responsabilidades según el nivel de sacrificio atribuido a cada grupo o personaje, pero, especialmente, según el valor simbólico asignado a su legado. A quien se atribuye más riesgo o pérdida, y con estos, aportes a la patria, por ejemplo San Martín o Belgrano, más alto se lo ubica en la escala. 
De esta manera, los valores morales positivos son atribuidos sólo a los protagonistas y, entre ellos, de manera gradual, en mayor medida a quienes se les atribuyen mayores sacrificios. Esta moral del sacrificio pareciera contribuir al mantenimiento de un imaginario social que justifica y enaltece a los sujetos del presente que padecen las consecuencias más graves de la desigualdad social, a pesar de que tengan la certeza de estar obteniendo muy poco de la sociedad nacional en la que viven.

La historia aprendida da cuenta, además, de la interiorización de un imaginario social de Independencia y libertad restringido casi exclusivamente al pasado de la nación, sin aplicación posible al curso de la sociedad actual. La eliminación del azar del origen histórico de la nación y su dependencia de la voluntad indefectible de unos cuantos elegidos y sacrificados es, justamente, un reflejo del esencialismo antes señalado.

Al trasladarse este mismo esquema a la comprensión del presente, la enseñanza de la historia en la escuela podría estar contribuyendo a la construcción de imaginarios sociales en los que la iniquidad social se naturaliza, y los chicos de sectores marginales asumen con resignación la exclusión padecida y un rol de perpetua subordinación, algo que requiere ser corregido a toda costa, si la enseñanza de la historia se vislumbra desde un horizonte moral, más complejo, rico y crítico que el que hemos encontrado aquí.】 


\section{Bibliografía}

Anderson, B. (1983). Comunidades imaginadas. Reflexiones sobre el origen y la difusión del nacionalismo. México: Fondo de Cultura Económica.

Barton, K., y Levstik, L. (2004). Teaching History for the Common Good. New Yersey: Earlbaum.

Barton, K. y Levstik, L. (2008). 'History'. En Arthur, J., Hahn, C., y Davies, I. (Eds.) Handbook of education for citizenship and democracy, 355-366. Londres: Sage.

Beck, I., y Mckeown, M. (1994). 'Outcomes of history instruction: Pasteup accounts'. En Carretero, M., y Voss, J. (Eds.) Cognitive and instructional processes in history and the social sciences. Hillsdale, New Yersey: Erlbaum.

Borges, J. L. (2008). Atlas. Buenos Aires: Emecé.

Borón, A. (2000). Tras el búho de Minerva. Mercado contra democracia en el capitalismo de fin de siglo. Buenos Aires: Fondo de Cultura Económica-Consejo Latinoamericano de Ciencias Sociales.

Carretero, M. (2007). Documentos de identidad. La construcción de la memoria histórica en un mundo global. Buenos Aires: Paidós.

Carretero, M., Jacott, L., y López-Manjón, A. (1994). 'Comprensión y enseñanza de la causalidad histórica'. En Carretero, M. Construir y enseñar las ciencias sociales y la historia. Buenos Aires: Aique.

Carretero, M., y Kriger, M. (2006a). 'La usina de la patria y la mente de los alumnos. Un estudio sobre las representaciones de las efemérides escolares argentinas'. En Carretero, M., Rosa, A., y González, M. F. (Comp.) Enseñanza de la historia y memoria colectiva. Buenos Aires: Paidós.

Carretero, M. y Kriger, M. (2006b). 'Enseñanza de la historia y formación ciudadana: Representaciones del pasado y proyecciones del futuro de los jóvenes argentinos'. Espacios en Blanco, Serie Indagaciones, No. 16 (Julio), 17-46.

Donovan, M. S., y Bransfrod, J. D. (2005). How Students Learn. History, Mathematics, and Sciences in the Classroom. Washington: The National Academies Press.

Egan, K. (1997). The Educated Mind. Chicago: Londres: University of Chicago Press. [En castellano: Mentes educadas. Cultura, instrumentos cognitivos y formas de comprensión. Barcelona: Paidós, 2000].
Escobar, A. (1996). La invención del tercer mundo. Bogotá: Norma.

González, M. F. (2005). Representaciones de imágenes y narrativas históricas en la construcción de la identidad nacional. Un estudio comparativo entre Argentina, Chile y España. Tesis. Doctorado en Psicología, Universidad Autónoma de Madrid.

Kriger, M. (2007). Historia, identidad y proyecto. Un estudio de las representaciones de los jóvenes argentinos, sobre el pasado, presente y futuro de la nación. Tesis. Doctorado en Ciencias Sociales. Facultad Latinoamericana de Ciencias Sociales FLACSO, Sede Académica Argentina.

Kriger, M. (2010). Jóvenes de escarapelas tomar. Escolaridad, comprensión histórica y formación política en la Argentina contemporánea. La Plata: Edulep, Editorial de la Universidad de la Plata.

Mignolo, W. (2005). The idea of Latin America. Oxford: Blackwell Publishing [En castellano: La idea de América Latina. Madrid: Gedisa, 2007].

Monsiváis, C. (2000). Aires de familia. Cultura y sociedad en América Latina. Barcelona: Anagrama.

Quijano, A. (2000). 'Colonialidad del saber, eurocentrismo y América Latina'. En Lander, E. (Comp.) La colonialidad del saber: eurocentrismo y ciencias sociales. Perspectivas latinoamericanas. Buenos Aires: Consejo Latinoamericano de Ciencias Sociales - UNESCO.

Rama, Á. (1982). Transculturación Narrativa en América Latina. México: Siglo XXI.

Renan, E. (2001) ¿Qué es una nación? Madrid: Sequitur.

Ricoeur, P. (2000). La Memoire, l'histoire, lóubli. París: Éditions du Seuil [En castellano: La Memoria, la historia, el olvido. Madrid: Trotta, 2003].

Romero, L. A. (2004). La Argentina en la escuela. La idea de nación en los textos escolares. Buenos Aires: Siglo XXI.

Rosa, A. (1994). 'What do people consume history for? (If they do). Learning history as a process of knowledge conception and construction of meaning. En Carretero, M., y Voss, J. (Comps.) Cognitive and Instructional Processes in History and Social Sciences. Hillsdale - New Jersey: Erlbaum. 
Ruiz Silva, A. (2008). El diálogo que somos. Ética discursiva y educación. Bogotá: Cooperativa Editorial Magisterio.

Ruiz Silva, A. (2009). La nación en los márgenes. Estudio de los elementos de carácter representacional, moral y político en relatos de nación de jóvenes de últimos grados de secundaria, de una escuela pública, en el conurbano bonaerense. Tesis. Doctorado en Ciencias Sociales. Facultad Latinoamericana de Ciencias Sociales FLACSO -Sede Académica Argentina-

Ruiz Silva, A. (2010). Nación, moral y narración. La Argentina en los márgenes y el aprendizaje de la historia. Manuscrito en preparación.

Taylor, Ch. (2004). Modern Social Imaginaries. DurhamLondres: Duke University Press. [En castellano: Imaginarios sociales modernos. Barcelona: Paidós, 2006].

Torres G., J. (1941). Universalismo Constructivo. Buenos Aires: Poseidón.

Vansledright, B. (2008). 'Narratives of Nation-State, Historical Knowledge, and School History Education'. Review of Research in Education, Vol. 32, 109-146.

Voss, J., Ciarrochi, J., y Carretero, M. (2004). 'La causalidad histórica: acerca de la comprensión "intuitiva” de los conceptos de suficiencia y necesidad'. En Carretero, M., y Voss J. (Comp.) Aprender y pensar la historia. Buenos Aires: Amorrortu.
Wertsch, J. (1994). 'Struggling with the past: Some dynamics of historical representation'. En Carretero, M., y Voss, J. (Eds.) Cognitive and instructional processes in history and the social sciences. Hillsdale-New Jersey: Erlbaum, 323-338.

Wertsch, J. (1998). Mind as Action. New York: Oxford University Press [En castellano: La mente en acción. Buenos Aires: Aique, 1998].

Wertsch, J. (2004). 'Specific Narratives and Schematic Narrative Templates'. En Seixas, P. (Ed.) Theorizing Historical Consciousness. Toronto: University of Toronto Press, 49-62.

Wertsch, J., y O’Connor, K. (1994). 'Multivoicedness in historical representation: American college students' accounts of the origins of the United States'. Journal of Narrative and Life History. 4 (4), 295-309.

White, H. (1973). Metahistoria. La imaginación histórica en la Europa del siglo XIX. México: Fondo de Cultura Económica.

White, H. (1978). Tropic of Discourse. Baltimore-Londres: Johns Hopkins University Press. [En castellano: El texto histórico como artefacto literario. Barcelona: Paidós, 2003a].

White, H. (2003b) 'Hecho y figuración en el discurso histórico'. En El texto histórico como artefacto literario. Barcelona: Paidós. 